\title{
REICH E A POSSIBILIDADE DO BEM-ESTAR NA CULTURA
}

\author{
Paulo Albertini ${ }^{1}$ \\ Instituto de Psicologia - USP
}

\begin{abstract}
Numa entrevista dada em 1952, Reich afirmou que o texto freudiano $\mathrm{O}$ mal-estar na cultura fora escrito em resposta a uma conferência que proferira na casa do Freud sobre o tema profilaxia das neuroses. Inspirado nesse depoimento, este trabalho procura investigar as teses reichianas que se contrapõem ao pensamento freudiano de $\mathrm{O}$ mal-estar na cultura. Diferenciam-se as posições dos autores a partir das idéias de conflito inevitável (Freud) e de possibilidade de harmonia (Reich). As principais noções focalizadas são as de: sexualidade, agressividade $e$ formação reativa.
\end{abstract}

Descritores: Reich, Wilhelm. Freud, Sigmund. Sexualidade. Agressividade. Formação reativa.

$\mathrm{E}^{\mathrm{s}}$ m 18 e 19 de outubro de 1952, Reich foi entrevistado por um representante dos Arquivos Sigmund Freud. Neste valioso material de caráter biográfico, com cerca de 100 páginas entre perguntas, respostas e notas explicativas dos editores, Reich recorda, comenta e analisa sua ampla e complexa relação com Freud e com a instituição psicanalítica. O longo depoi-

1 Endereço para correspondência: Instituto de Psicologia da Universidade de São Paulo. Av. Prof. Mello Moraes, 1721 - 05580-900 - São Paulo, SP. Endereço eletrônico: albertin@usp.br

Psicologia USP, 2003, 14(2), 61-89 
mento foi gravado e publicado em livro (Higgins \& Raphael, 1967/1979). ${ }^{2}$ O objetivo da entrevista mostra-se claro na primeira pergunta formulada:

Dr. Reich, a pergunta que lhe quero fazer é muito simples. É uma pergunta muito ampla, mas uma pergunta simples. Gostaria que me dissesse tudo que sabe acerca de Freud, tudo que observou e tudo o que pensou. Mesmo que isso não seja baseado numa observação correcta, o simples facto de que o tenha pensado acerca de Freud será já bastante importante para que o saibamos. (p. 19)

Para os objetivos deste trabalho, interessa-nos especialmente destacar uma resposta que Reich formula ao recordar um aspecto central de sua divergência com Freud: o tema da felicidade e da infelicidade humana. Sobre esse assunto, em certa altura da entrevista, afirma algo surpreendente sobre o artigo freudiano "O MalEstar na Cultura": "Quero que fique bem claro que Das Unbehagen in der Kultur [O MatEstar na Cultura] foi escrito especificamente em resposta a uma das minhas conferências, apresentada em casa de Freud. Era eu que estava 'Unbehaglich in der Kultur' [aproximadamente, 'Sentindo makestar na cultura' 3 ]" (p. 53).

Na sequiência da entrevista, fica claro que a conferência a que Reich se refere, não por acaso criticada por Freud, versava sobre o tema profilaxia das neuroses; algo impensável dentro do modelo freudiano, que postula a presença da neurose como uma condição inerente ao processo civilizatório.

Sem elementos para avaliarmos a veracidade do dado histórico revelado por Reich, podemos, isso sim, investigar as justificativas teóricas do entrevistado para se contrapor ao mestre em relação a algumas idéias centrais presentes em "O MarEstar na Cultura" (Freud, 1930/1974). ${ }^{4}$ A fim de

2 A primeira data refere-se à publicação original, a segunda à edição utilizada neste artigo. Empregamos esse critério para a citação de textos mais antigos, aqueles em que o conhecimento da data da edição original pode ser importante.

3 Agradeço a colaboração de Luiz Hanns com relação a algumas dúvidas de tradução do alemão para o português.

4 Na Edição Standard Brasileira das Obras Psicológicas Completas de Sigmund Freud esse texto foi traduzido como "O Mal-Estar na Civilização". Apesar de utili- 
cumprirmos tal proposta, organizamos este trabalho em quatro tópicos: no primeiro, denominado Freud e o conflito inevitável, analisamos algumas teses básicas de "O MatEstar na Cultura"; no segundo, intitulado Raízes do pensamento reichiano em Freud, procuramos mostrar os principais conceitos freudianos com que Reich se instrumentalizou para desenvolver a sua abordagem; no terceiro, Reich e a possibilidade de harmonia, o leitor vai encontrar as formulações desse autor que se contrapõem às posições freudianas expressas em "O MarEstar na Cultura"; no quarto, apresentamos algumas Considerações finais.

\section{Freud e o conflito inevitável}

Como se sabe, "O MatEstar na Cultura" está centrado na tese do antagonismo inevitável entre satisfação pulsional e exigências da cultura. Segundo essa orientação, já presente nos primeiros escritos freudianos, a civilização implica em algum grau de renúncia à satisfação pulsional. Freud, explicando essa posição por meio de material psicanalítico, usa como modelo o domínio do fogo pelo homem, sua utilização como um bem cultural a partir de uma renúncia à satisfação de um desejo, no caso, um desejo infantil de apagar o fogo com um jato de urina. Nas palavras do autor:

A primeira pessoa a renunciar a esse desejo e a poupar o fogo pôde conduzi-lo consigo e submetê-lo a seu próprio uso. Apagando o fogo de sua própria excitação sexual, domara a força natural do outro fogo. Essa grande conquista cultural foi assim a recompensa de sua renúncia ao instinto. (p. 110)

Além de relacionar civilização com necessidade de renúncia, Freud, nesse mesmo texto, supõe que no ser humano a função sexual estaria em processo de involução, tal como "parece acontecer com nossos dentes e cabelos.” (p. 126). A explicação para esse entendimento está fundamentada em

zarmos essa edição, no caso do título desse trabalho, optamos por "O Mal-Estar na Cultura”. 


\section{Paulo Albertini}

uma elaboração de orientação antropológica, que recebeu o nome de recalque orgânico, formulada como hipótese em duas extensas notas de rodapé. Em síntese, segundo essa teorização, quando da adoção da postura ereta pelo homem, seus órgãos genitais, anteriormente ocultos, tornaramse visíveis. A adoção da postura ereta teria, então, precipitado, como numa cadeia inexorável de acontecimentos, uma série de transformações nesse ser.

A exposição dos órgãos sexuais engendrou o aparecimento do sentimento da vergonha e a visão passou a ocupar o lugar do olfato como forma primordial de estimulação sexual, sofrendo esta última um processo de recalcamento. Assim, houve a passagem da atração sexual por meio de um determinado odor, presente apenas em certos períodos, para a estimulação contínua estabelecida pela visão; essa estimulação sexual constante teria gerado a formação de famílias. Além disso, com o recalcamento da atração via forte cheiro, certos odores, secreções e excrementos passaram a provocar repugnância, suscitando uma tendência humana à limpeza e, também, uma limitação na estimulação sexual, sempre que esses odores tornamse muito intensos. Com isso ocorreu uma diminuição do erotismo anal e, mesmo que em menor grau, da sexualidade como um todo. No texto freudiano:

Com a adoção de uma postura ereta pelo homem e a depreciação de seu sentido olfativo, não foi apenas o seu erotismo anal que começou a cair como vítima da repressão orgânica, mas toda sua sexualidade, de tal maneira que, desde então, a função sexual foi acompanhada por uma repugnância que não pode ser explicada por outra coisa, e que impede a sua satisfação completa, forçando -a a desviar-se do objetivo sexual em sublimações e deslocamentos libidinais. (p. 127)

Em suma, com a adoção da postura ereta, surgiu esse ser complexo, com uma sexualidade contínua, mas marcado, também, por sentimentos de vergonha e repugnância. Sentimentos esses que vão colocar limites à satisfação sexual e incitar o deslocamento da sexualidade, por meio do processo de sublimação, para outros caminhos. Esse deslocamento da sexualidade para outros caminhos é o que possibilitou a construção da civilização.

Cabe pontuar que, assim como bem observou Vieira (1994), o recalque orgânico é anterior ao recalque originário, este vinculado a eventos as- 
sociados ao assassinato do pai na horda primitiva e à geração das protofanta$\operatorname{sias}^{5}$ que caracterizam o Complexo de Édipo. Lançando mão de uma expressão freudiana, o recalque orgânico refere-se a algo "mais pofundo" e, além disso, como o próprio nome indica, orgânico; o que sugere tanto uma anterioridade temporal, como a constituição de algo que passou a fazer parte da esfera orgânica do homem.

Vale ressaltar que a presença de idéias ligadas à concepção do recalque orgânico já estão contidas em trabalhos publicados em anos mais iniciais da construção freudiana. Por exemplo, no clássico sobre a sexualidade humana "Três Ensaios sobre a Teoria da Sexualidade" (1905/1974), pode-se observar um modelo de entendimento do desenvolvimento psicossexual fundamentado na existência de um conflito interno, no qual as forças de vergonha e repugnância desempenham um importante papel. Assim, logo no primeiro ensaio, Freud manifesta que: "A repugnância parece ser uma das forças que levaram a uma restrição da vida sexual.” (p. 153). Mais adiante, em uma nota de rodapé, abordando a questão do fetiche, escreve: "Tanto os pés como os cabelos são objetos de forte odor que foram exaltados como fetiches após a sensação olfativa ter-se tornado desagradável e ter sido abandonada" (pp. 156-157). Ainda nesse artigo cita a vergonha e a repugnância como forças que atuam como resistência à sexualidade (p. 164) e associa à histeria um incremento da tendência à repugnância (pp. 153, 167). Por fim, numa observação vinculada ao campo educacional, sustenta a posição de que as barreiras à sexualidade não são criadas pela educação, pois esta apenas caminha num sentido já organicamente marcado. No texto:

Tem-se das crianças civilizadas uma impressão de que a construção dessas barreiras ${ }^{6}$ é um produto da educação, e sem dúvida a educação muito tem a ver com ela. Mas, na realidade, este desenvolvimento é organicamente determinado e fixado pe-

5 De acordo com Laplanche e Pontalis (1967/1983), "Estruturas fantasmáticas típicas (...) que a psicanálise descobre organizando a vida fantasmática, sejam quais forem as experiências pessoais dos indivíduos" (pp. 486-487).

6 As barreiras à sexualidade citadas por Freud são "a repugnância, os sentimentos de vergonha e as exigências dos ideais estéticos e morais" (p. 181). 
la hereditariedade, e pode ocasionalmente ocorrer sem qualquer auxílio da educação (p. 181)

De acordo com os objetivos do nosso trabalho, um outro ponto que merece ser analisado diz respeito ao lugar ocupado pelo mecanismo de defesa da formação reativa na teorização freudiana. Abordemos, primeiramente, o conceito de formação reativa. Trata-se, em síntese, segundo Laplanche e Pontalis (1967/1983), de uma "Atitude ou hábito psicológico de sentido oposto a um desejo recalcado (...) (o pudor opor-se a tendências exibicionistas, por exemplo)." (p. 258). Sem entrarmos nas várias peculiaridades que envolvem esse mecanismo de defesa, gostaríamos de evidenciar um aspecto que nos parece fundamental na diferenciação entre as posições de Freud e Reich. Esse aspecto pode ser resumido na seguinte questão: a formação reativa deve ser entendida como um mecanismo de defesa vinculado, exclusivamente, ao domínio patológico; ou se trata de algo que, necessariamente, faz parte da estruturação humana?

A nosso ver, no pensamento freudiano, ao contrário do que pode ser observado no enfoque reichiano, existem fortes argumentos no sentido de que a formação reativa é parte integrante da formação do homem. Pode-se supor que o próprio conteúdo que tende a aparecer no período de latência - a vergonha, a repugnância e a moralidade - e que se opõe como barreira à exuberância sexual presente na fase fálica, pode ser interpretado como uma espécie de formação reativa. De certa maneira, Freud (1905/1972) assume essa orientação em "Três Ensaios sobre a Teoria da Sexualidade", ao considerar a formação reativa como uma subespécie de sublimação. Nas palavras do autor: "Uma subespécie de sublimação pode ser encontrada na supressão pela formação reativa, que, como vimos, começa no período de latência de uma criança e continua, em casos favoráveis, por toda sua vida" (p. 246). Como se vê, nesse texto destinado a expor o nada linear desenvolvimento psicossexual do ser humano, com fases que apresentam diferentes tendências dominantes, esse mecanismo psíquico, que descreve justamente movimentos de ação e reação, ocupa papel de destaque. Já em "O MałEstar na Cultura", em vários momentos, Freud cita e emprega a formação reativa 
para descrever e analisar fenômenos. Assim, quando discute as modificações que o processo civilizatório teria acarretado nas disposições instintivas humanas, menciona, como exemplo, o aparecimento das tendências à limpeza, ordem e parcimônia como substitutos ao erotismo anal das crianças e dos seus interesses pelas funções excretoras. Deve-se notar que o autor vai considerar essas orientações substitutas como patológicas, apenas nos casos em que as mesmas aparecem muito intensificadas, gerando o caráter anal. Fora desse registro do exagero, elas contribuem para a formação do homem.

E qual a vinculação dos conceitos da repressão orgânica e da formação reativa com as idéias defendidas por Freud em "O Mal-Estar na Cultura"? Segundo nossa percepção, em ambos os casos, há a suposição de um conflito interno entre diferentes tendências e, o que é mais importante, esse conflito é parte constituinte do homem, não podendo ser evitado por qualquer espécie de reforma social.

Assim, até aqui, desenvolvemos principalmente dois temas associados ao artigo "O Mal-Estar na Cultura": o do recalque orgânico e o do papel da formação reativa na teorização freudiana. Passemos, agora, a focalizar um outro assunto que escolhemos para expor e que, posteriormente, iremos analisar segundo a orientação reichiana: a questão da agressividade humana.

$\mathrm{Na}$ organização dos escritos freudianos sugerida por Mezan (1991), não por acaso, o último período (de 1920 a 1939) recebe o nome de Sobo signo de Thânatos. Sem dúvida, nessa etapa da produção freudiana, a pulsão de morte, idéia lançada apenas como hipótese no trabalho "Além do Princípio do Prazer" (1920/1976), progressivamente, vai assumindo um papel fundamental na metapsicologia psicanalítica. Pode-se dizer que boa parte de "O Mal-Estar na Cultura" é dedicada a esse tema. Vejamos um trecho em que o autor mostra claramente a sua concepção a respeito do potencial agressivo humano:

Os homens não são criaturas gentis que desejam ser amadas e que, no máximo, p odem defender-se quando atacadas; pelo contrário, são criaturas entre cujos dotes instintivos deve-se levar em conta uma poderosa cota de agressividade. Em resultado disso, o seu próximo é, para eles, não apenas um ajudante potencial ou um objeto sexual, mas alguém que os tenta a satisfazer sobre ele a sua agressividade, a 
explorar sua capacidade de trabalho sem compensação, utilizálo sexualmente sem seu consentimento, apoderar-se de suas posses, humilhálo, causar-lhe sofrimento, torturá-lo e matá-lo. (p. 133)

É necessário observar que Freud não está se referindo a um homem de determinada cultura ou situação social; o seu texto abrange o homem como essência, como categoria ontológica. Em decorrência desse posicionamento em relação à agressividade humana, o autor, de forma coerente, mostra-se cético frente a propostas que exijam a presença de uma solidariedade humana universal. A razão para esse ceticismo aparece explicitada de forma cristalina na seguinte afirmação: "É sempre possível unir um considerável número de pessoas no amor, enquanto sobrarem outras pessoas para receberem as manifestações de sua agressividade.” (p. 136). De acordo com essa máxima, os judeus, espalhados pelo mundo, teria m prestado bons serviços aos povos que os acolheram, ao servirem como possibilidade de descarga agressiva e, com isso, contribuírem para uma maior coesão grupal desses povos. Ainda manifestando tal visão sobre o homem, e, consequentemente, duvidando das premissas psicológicas do comunismo, alfineta: "Não se pode senão imaginar, com preocupação, sobre o que farão os soviéticos depois que tiverem eliminado seus burgueses." (p. 137).

Contudo, a bem da verdade, essa leitura a respeito do potencial destrutivo humano primário deve ser matizada pela consideração de outros componentes do conjunto freudiano.

De início, cabe avaliar o papel desempenhado pelas pulsões de vida, ou Eros, o outro pólo do último modelo de dualidade pulsional da metapsicologia freudiana. Essa corrente pulsional, ao contrário das pulsões de morte, visa a ligar, juntar, atuando no sentido do estabelecimento e da manutenção de unidades cada vez mais abrangentes. Como a maior parte das ações humanas contém mesclas desses dois pólos, um, de certa forma, tende a minimizar a direção imprimida pelo outro. A partir dessa consideração, é possível entender a argumentação freudiana, que vê na necessidade da restrição da sexualidade uma forma de gerar libido para possibilitar identifica- 
ções e relacionamentos amorosos inibidos em sua finalidade e, com isso, desviar Eros para aplacar a ação de Thânatos. Em "O MarEstar na Cultura":

A civilização tem de utilizar esforços supremos a fim de estabelecer limites para os instintos agressivos do homem... Daí, portanto, o emprego de métodos destinados a incitar as pessoas a identificações e relacionamentos amorosos inibidos em sua finalidade, daí a restrição à vida sexual e daí, também, o mandamento ideal de amar ao próximo como a si mesmo, mandamento que é realment e justificado pelo fato de nada mais ir tão fortemente contra a natureza original do homem. (Freud, 1930/1974, p. 134)

Além disso, a nosso ver, o caminho trilhado por Freud deve ser apreendido como, de alguma forma, associado a um projeto de cunho iluminista, este afinado com uma tradição vinculada ao humanismo burguês do Renascimento. Essa tradição, ao contrário da visão teocêntrica predominante no período medieval, vai colocar o homem como centro e defender a possibilidade de seus componentes instintivos serem vividos sob a organização da razão humana. ${ }^{7}$ Nessa perspectiva, a construção freudiana pode ser vista como uma ampla elaboração, muitas vezes dura e crua, como em "O Mał Estar na Cultura", do potencial irracional e destrutivo do homem, não para a submissão ao mesmo, mas, com o sentido oposto, para haver alguma chance de dominá-lo por meio da tomada de consciência e da influência das chamadas instâncias psíquicas superiores. Assim se ndo, pode-se interpretar "O Mal-Estar na Cultura" como uma espécie de "pedagogia da realidade" e, consequentemente, como uma crítica mordaz a formas alienantes e adocicadas de leitura da realidade humana. Sobre o papel da razão no modelo freudiano, a título de ilustração, gostaríamos de lembrar um esclarecedor trecho, não por acaso presente no artigo "O Futuro de uma Ilusão" (Freud, 1927/1974). No texto:

A voz do intelecto é suave, mas não descansa enquanto não consegue uma audiência. Finalmente, após uma incontável sucessão de reveses, obtém êxito. Esse é um dos poucos pontos sobre o qual se pode ser otimista a respeito do futuro da huma-

7 Sobre essa aproximação entre a psicanálise freudiana e o humanismo do Renascimento, ver a análise presente em Albertini (1997). 
nidade, e, em si mesmo, é de não pequena importância. E dele se podem derivar outras esperanças ainda. A primazia do intelecto jaz, é verdade, num futuro muito distante, mas, provavelmente, não num futuro infinitamente distante. (p. 68)

Devemos, por fim, acrescentar um outro motivo sustentado por Freud para fundamentar a sua tese da impossibilidade da completa satisfação sexual humana. Esse motivo refere-se ao grau de participação e fruição das pulsões de morte no relacionamento erótico, os quais, segundo o autor, poderiam colocar o objeto amoroso em risco. Assim, citando argumentos em favor da sua tese, Freud (1930/1974) afirma:

Outra dificuldade surge da circunstância de tão freqüentemente achar-se associada ao relacionamento erótico, além e acima de seus próprios componentes sádicos, uma cota de inclinação pura à agressão. O objeto amoroso nem sempre encarará essas complicações com o grau de compreensão e tolerância demonstrado pela camponesa, ao se queixar de que seu marido não a amava mais, pois havia uma semana que não a espancava. (p. 127)

Após esse percurso pelo pensamento freudiano contido em "O Mał Estar na Cultura”, faremos, a seguir, uma breve apresentação, mais conceitual do que histórica, da participação de Reich na psicanálise. Nosso intuito com esse tópico é, além de expor aspectos centrais do enfoque reichiano, principalmente mostrar quais noções freudianas serviram de base para 0 desenvolvimento da abordagem reichiana.

\section{Raízes do pensamento reichiano em Freud}

O austríaco Wilhelm Reich foi formalmente aceito como membro da Associação Psicanalítica Internacional em outubro de 1920, aos 23 anos (maiores detalhes em Albertini, 1994). Nessa instituição permaneceu até 1934, quando, por razões de diversas ordens, foi expulso. ${ }^{8}$ No campo con-

8 Uma análise acurada dos fatores que envolveram essa expulsão - principalmente os associados ao perigo que representava para a Associação Psicanalítica manter em seus quadros alguém como Reich, na época um militante comunista que combatia 
ceitual, a ligação da abordagem reichiana com o pensamento freudiano deve ser buscada em um conjunto de noções relacionadas ao chamado ponto de vista econômico, aquele destinado a focalizar a magnitude dos fenômenos psíquicos, a sua dimensão quantitativa. ${ }^{9}$ Essas noções afinadas com o ponto de vista econômico dizem respeito, principalmente, às concepções de neurose atual e de estase da libido.

A expressão "neurose atual" apareceu pela primeira vez em "A Sexualidade na Etiologia das Neuroses" (Freud, 1898/1976) e foi criada para classificar dois quadros neuróticos, a neurastenia e a neurose de angústia, descritos por Freud (1895/1976) em um trabalho anterior denominado "Sobre os Critérios para se Destacar da Neurastenia uma Síndrome Particular Intitulada "Neurose de Angústia'“. Em síntese, de acordo com o entendimento freudiano, nas neuroses atuais a sintomatologia seria de ordem psicossomática (principalmente na neurastenia) e, diferentemente das psiconeuroses (basicamente a histeria e a neurose obsessiva), a etiologia deveria ser procurada em desordens da vida sexual atual, e não em conflitos ligados ao período infantil. $\mathrm{O}$ fator decisivo no campo das neuroses atuais seria a magnitude do acúmulo ou da descarga de libido na atualidade. Assim, na neurose de angústia haveria um excesso de energia, produto, especialmente, de abstinência sexual ou da prática de coito interrompido; já na neurastenia, ao contrário, haveria uma descarga acentuada de libido, em geral vinculada à masturbação excessiva. Como se sabe, Freud pouco desenvolveu a teoriza-

abertamente o nazismo ascendente na Alemanha - pode ser encontrada em Wagner (1996). Segundo Ernest Jones: "Wilhelm Reich se exonerou da Associação. Freud o tinha em alta conta no começo de sua carreira, mas o fanatismo político de Reich conduziu tanto ao rompimento pessoal quanto ao científico" (Jones, 1961/1979, p. 736).

9 De acordo com Laplanche e Pontalis, o ponto de vista econômico: "Qualifica tudo o que se refere à hipótese segundo a qual os processos psíquicos consistem na circulação e repartição de uma energia quantificável (energia pulsional), isto é, sus ceptível de aumento, de diminuição, de equivalência” (1967/1983, p. 167). 


\section{Paulo Albertini}

ção a respeito das neuroses atuais ${ }^{10}$ e a técnica psicanalítica foi toda associada ao trabalho com as psic oneuroses.

Outro conceito freudiano que vai assumir um papel central na abordagem reichiana é o de estase da libido. Laplanche e Pontalis assim a definem:

Processo econômico que Freud supõe poder estar na origem da entrada na neurose ou na psicose: a libido que deixa de encontrar caminho para a descarga acumula-se sobre formações intrapsíquicas; a energia assim acumulada encontrará a sua utilização na constituição dos sintomas. (p. 220)

Cabe destacarmos uma clara proximidade entre os conceitos de estase da libido e de neurose atual: em ambos o olhar freudiano recai sobre a quantidade de libido que existe no presente. Baseado em tal semelhança, Reich vai chamar as neuroses atuais de neuroses estásicas. ${ }^{11}$ Em um artigo que contém uma série de idéias posteriormente adotadas e desenvolvidas por Reich, "Moral sexual 'civilizada' e Doe nça Nervosa Moderna", de 1908, Freud, atribuindo importância decisiva ao fator acúmulo de libido na atualidade, emprega a noção de estase da libido para descrever um processo de desencadeamento da psiconeurose. Segundo ele:

O valor psíquico da satisfação exual cresce com a sua frustração. A libido represada torna-se capaz de perceber os pontos fracos raramente ausentes da estrutura da vida sexual, e por ali abre caminho, obtendo uma satisfação substitutiva neurótica na forma de sintomas patológicos. Quem penetrar nos determinantes das doenças nervosas cedo ficará convencido de que o incremento dessas doenças em nossa sociedade provém da intensificação das restrições sexuais. (Freud, 1908/1976, p. 199)

10 Afinada com o referencial psicanalítico, a chamada Escola de Psicossomática de Paris, liderada por Pierre Marty, há várias décadas vem desenvolvendo trabalhos inspirados em alguns pontos da conceituação freudiana sobre as neuroses atuais. Sobre o assunto, ver Ferraz (1997).

11 Um desenvolvimento completo dessa aproximação entre neurose atual e estase da libido pode ser venficado em Reich (1942/1978, pp. 83-88). 
Em 1942, tendo por base o conceito freudiano de estase da libido, Reich assim explica a importância dos fatores atuais na etiologia das psiconeuroses:

Como resultado de uma inibição atual, experiências da infância, em si mesmas não patológicas, podem, por assim dizer, receber um excesso de energia sexual. Se isso acontecer, tornam-se insistentes, entram em conflito com a organização psíquica adulta e têm, de então em diante, que ser mantidas sob controle com a ajuda da repressão. É assim que uma psiconeurose crônica, com seus conteúdos sexuais infantis, se desenvolve de uma inibição sexual causada no presente e, a princípio, "inofensiva". Isso é a essência do que Freud descreveu como "regressão neurótica aos mecanismos infantis" ... Mesmo que a neurose não tenha existido desde a infância, desenvolvendo-se mais tarde, ainda assim o que se verifica é que uma inibição sexual "normal", ou uma dificuldade na vida sexual do indivíduo, produziu uma estase; essa estase, por sua vez, ativou os desejos incestuosos e as angústias sexuais infantis. (1942/1978, p. 88)

Se o problema é a estase, considerada por Reich como a fonte de energia do sintoma, o autor vai supor que, no caso do adulto, a principal forma de descarregar a energia acumulada seria propiciada pela satisfação sexual genital - a que tende a descarregar a maior quantidade de libido. $\mathrm{O}$ objetivo seria a manutenção de uma economia da libido regulada, ou, em outras palavras, um estado de equilíbrio entre carga e descarga de energia que não possibilitasse condições para a formação de estase. É com esse entendimento que surge o estudo do orgasmo no pensamento reichiano. Cabe lembrar que o próprio Freud, em, no mínimo, duas passagens de "Moral Sexual ‘Civilizada' e Doença Nervosa Moderna”, sustenta posições congruentes com o caminho tomado por Reich com relação à importância da satisfação sexual para a saúde. Isso pode ser observado, por exemplo, na seguinte afirmação: "A meu ver, a satisfação sexual é a melhor proteção contra a ameaça que as disposições inatas anormais ou os distúrbios do desenvolvimento constituem para uma vida sexual normal" (Freud, 1908/1976, pp. 198-199). Ou ainda:

Para a grande maioria das organizações parece ser indispensável uma certa quantidade de satisfação sexual direta, e qualquer restrição dessa quantidade, que varia de indivíduo para indivíduo, acarreta fenômenos que, devido aos prejuízos funcionais 
e ao seu caráter subjetivo de desprazer, devem ser considerados como uma doença. (Freud, 1908/1976, pp. 193-194)

Não faz parte dos objetivos deste trabalho desenvolver as várias e complexas questões ligadas ao conceito de orgasmo na abordagem reichiana. Contudo, pelo menos dois aspectos nodais desse tema não podem deixar de serem explicitados. Um deles diz respeito ao fato de Reich ter iniciado a elaboração nessa área, focalizando especificamente o orgasmo sexual, mas, com o desenvolvimento da sua teorização, o autor estabeleceu uma aproximação entre o domínio tradicionalmente entendido como sexual e as demais esferas da vida. Assim, de acordo com essa ampliação, o importante é a capacidade de envolvimento e entrega, isso em qualquer atividade específica que se realize. No seguinte trecho o autor explica essa idéia:

$\mathrm{O}$ abraço natural ${ }^{12}$ pleno assemelharse a uma escalada; ele não se distingue essencialmente de qualquer atividade vital, importante ou não. Viver na plenitude é se abandonar ao que se faz. Pouco importa que se trabalhe, que se fale com amigos, que se eduque uma criança, que se escute uma conversa, que se pinte um quadro, que se faça isso ou aquilo. (Reich, 1953/1982, p. 32)

Além disso, Reich entende haver descoberto, por meio do estudo da sexualidade, uma função biológica fundamental e primária que comporta dois momentos básicos: carga-descarga, tensão-distensão, contraçãoexpansão. A partir dessa concepção, o autor passou a utilizar o seu modelo de leitura descoberto no estudo do orgasmo sexual para investigar outros fenômenos da vida, como, por exemplo, a divisão celular, na qual uma célula com alta tensão interna se divide e, com isso, restabelece o seu equilíbrio energético. Seguindo essa linha de interpretação, o modelo reichiano pode ser empregado para auxiliar a compreensão dos mais diversas eventos: desde os estados relativamente duradouros de tensão não acompanhados por relaxamento - o estresse -; passando pelo ciclo menstrual, que comporta tensão e acúmulo de líquidos seguido por descarga e relaxamento; até o chamado "relaxamento natural", esperado no universo das práticas esporti-

12 Expressão utilizada por Reich para se referir ao ato sexual. 
vas, após uma conquista que demandou intensa concentração e alta tensão numa disputa. Em outro trabalho (Albertini, 1997), exemplificamos a leitura propiciada pelo enfoque proposto por Reich, imaginando um encontro de amigos com dois desfechos. No primeiro: "A conversa flui com facilidade, o tempo passa rapidamente... Após terem falado, trocado, brincado, os assuntos vão se esgotando, o encontro está chegando ao fim. Os amigos se despedem e, com ar de satisfação, voltam para suas vidas." (p. 63). No segundo: "eles se encontram, conversam, mas, por algum motivo que não conseguem identificar, a conversa não flui ... O tempo passa com dificuldade (...) está na hora de ir embora ... Eles se despedem e, na verdade, vão embora com dificuldade." (p. 63). Em síntese, no primeiro caso, uma mudança de estado ocorreu, na linguagem reichiana, houve curva orgástica; no segundo, apesar do encontro, a tensão continuou presente, a estase permaneceu.

\section{Reich e a possibilidade de harmonia}

Apesar de Reich desenvolver um certo ramo conceitual freudiano, como exposto, o relacionado ao ponto de vista econômico, nos anos finais da década de 20, ele vai se opor fortemente aos caminhos tomados por Freud. A fim de focalizarmos este embate teórico, escolhemos como material norteador o trabalho de Reich denominado "O Caráter Genital e o Caráter Neurótico". Este artigo foi publicado, originalmente, em 1929, na revista psicanalítica Internationale Zeitschrift für Psychoanalyse (ver Wilhelm Reich: Biographical material, 1953, p. 19), e editado, novamente, como um capítulo do livro de Reich Análise do caráter, em 1933. Essa escolha foi motivada por duas razões básicas: a proximidade temporal dos dois escritos (O Mal-Estar na Cultura, de1930 e O Caráter Genital e o Caráter Neurótico, de 1929) e a similaridade dos temas tratados nas duas publicações.

Em linhas gerais, no trabalho “O Caráter Genital ...” Reich organiza o texto em dois extremos. De um lado, no pólo da saúde, ele supõe a possibilidade da existência de uma estrutura em que haveria um alto grau de harmonia intrapsíquica, o chamado caráter genital; de outro, no pólo da doença, 


\section{Paulo Albertini}

ele descreve a estrutura em que um intenso conflito interno se faz presente, o caráter neurótico. Deve-se registrar que o autor tem o cuidado de esclarecer que essa classificação refere-se a tipos ideais, e que, na verdade, os caracteres reais são estruturas mistas, que se aproximam mais de um ou outro extremo. Apesar de esse cuidado reichiano, tomando a proposta do trabalho "O Caráter Genital ..." como um todo, já de início é necessário observar que não faz parte da orientação freudiana qualquer tentativa de suposição de um estado de saúde, uma vez que, para o autor, a neurose seria um acompanhante constante da vida civilizada.

Numa apreciação global, como Reich concebe o seu ideal de saúde, o caráter genital?

Tendo como referência a importância que o autor atribui ao ponto de vista econômico na análise dos fenômenos, fica fácil perceber que o caráter genital está associado à presença de uma economia da libido regulada. No contexto da produção teórica reichiana do final dos anos 20, isso implicava, no caso do adulto, uma atividade sexual genital orgástica e, também, uma capacidade sublimatória. Para o autor essas duas formas de atividade sexual utilizariam pulsões diferentes; a sublimação, como o próprio Freud sugeriu, tenderia a ocorrer em função das chamadas pulsões parciais ${ }^{14}$, particularmente aquelas que não conseguem integrar-se na genitalidade. Além disso, Reich vai mais longe e afirma que a satisfação sexual genital gera melhores

13 Apesar disso, não se tratava, propriamente, de uma novidade na esfera psicanalítica postular um estágio genital do desenvolvimento da libido e aproximá-lo do domínio da saúde. O médico e psicanalista alemão Karl Abraham, um pioneiro no estudo do desenvolvimento da libido, em "A Formação do Caráter no Nível Genital do Desenvolvimento da Libido", de 1925, associou a esse estágio aspectos como, por exemplo, a superação de atitudes de ambivalência. Consciente dos riscos que tal teorização poderia acarretar, Abraham, nesse mesmo texto, alertou: "Uma vez que nos achamos no tópico do estágio definitivo da formação do caráter, convém prevenir uma possível má interpretação. Não é intenção deste estudo dizer exatamente o que é um caráter "normal'" (Abraham, 1925/1970, p. 199).

14 De acordo com Laplanche e Pontalis, "as pulsões parciais começam por funcionar independentemente e tendem a unir-se nas diversas organizações libidinais" (1967/1983, p. 516). 
condições para a ocorrência de sublimações; é como se, livre da maior urgência sexual, o homem ficasse mais disponível para o trabalho, por exe mplo. Assim, nessa linha de argumentação, o autor associa ao caráter genital uma maior capacidade de trabalho. Em suas palavras:

Na verdade, aprendemos que uma economia libidinal regulada é a condição prévia de uma sublimação bem sucedida e duradoura... A psicanálise das perturbações do trabalho ensina-nos que, quanto maior for a estase da libido como um todo, tanto mais difícil será sublimar a libido pré-genital. As fantasias sexuais absorvem os interesses psíquicos e distraem do trabalho... Soltar as tensões sexuais libera energia para realizações mais elevadas, porque durante um certo tempo as fantasias sexuais não arrastam para si qualquer investimento libidinal. (1933/1995, p.180)

Nesse ponto não devemos deixar de perceber uma diferença de fundo entre as perspectivas de Freud e Reich em relação ao tema sexualidade. Para o primeiro, como visto na parte inicial deste trabalho, a função sexual humana estaria em processo de involução e a civilização seria produto da restrição sexual; sem a mesma não haveria desvio de energia para a sua construção. O modelo é o de uma quantidade fixa de energia que, se for gasta inteiramente de uma forma, impossibilita outra maneira de emprego. Numa completa inversão da equação freudiana, para Reich, a vivência sexual orgástica geraria as melhores condições para a ocorrência de sublimações e, portanto, de cultura no seu sentido mais desenvolvido. O modelo não é o da distribuição de uma quantidade fixa de energia, mas de atividades que, se satisfatoriamente vividas, auxiliam-se: satisfação sexual direta e sublimação, amor e trabalho. Assim, pode-se afirmar que o autor substitui a tese freudiana da "sexualidade ou cultura" pela da "sexualidade e cultura". Além disso, na teorização de Reich formulada no final dos anos 20, as dificuldades sexuais não são explicadas por hipóteses como a do recalque orgânico - fator responsável por sentimentos de repugnância e vergonha que acompanhariam o desempenho da função sexual. Sua tendência é a de relacionar às dificuldades humanas, especialmente as sexuais, circunstâncias socioculturais passíveis de serem alteradas, e não conteúdos constitucionais do próprio homem. 


\section{Paulo Albertini}

Com relação à atividade intelectual, o mesmo modelo de auxílio mútuo pode ser verificado. Ou seja, para o autor, uma boa economia energética possibilita melhores condições para o pleno exercício da racionalidade e, esta, por sua vez, facilita o domínio, e não o recalque, de pulsões. De acordo com essa orientação, a preponderância da razão supõe a presença de uma estrutura caracteriológica que esteja vivendo num estado não matizado por estase libidinal. No seguinte trecho o autor sintetiza sua posição em relação à atividade intelectual:

Se a primazia do intelecto é a finalidade do desenvolvimento social, ela é inconcebível sem a primazia genital. A hegemonia do intelecto não só põe fim a uma sexualidade irracional como tem como condição prévia uma economia da libido regulada. (Reich, 1933/1995, p. 176)

E quanto ao caráter neurótico, de que moda Reich, no texto em tela, o formula? De maneira geral, essa estrutura é descrita como oposta ao caráter genital; em síntese, ela contém uma economia da libido não regulada e uma escassa capacidade sublimatória. Além disso, o que chama a atenção na descrição reichiana do caráter neurótico é a forte presença do mecanismo de defesa da formação reativa, ao invés da sublimação. Assim, por exemplo, na esfera do trabalho, o desempenho, ao invés de criativo, será marcado por uma ação compulsiva, repetitiva e com sérias dificuldades para ser interrompido. Vejamos como o autor diferencia o trabalho movido por processo sublimatório do efetuado por meio da formação reativa:

A formação reativa é espasmódica e compulsiva, enquanto a sublimação fluilivremente (...) O homem que sublima pode interromper seu trabalho por um considerável período de tempo...Contudo, quando um desempenho reativo é interrompido, mais cedo ou mais tarde surge uma inquietação interior. (Reich, 1933/1995, p. 181)

Neste momento, cabe pontuarmos que, como já discutido neste trabalho, no modelo freudiano a formação reativa deve ser entendida como um mecanismo integrante da estruturação do homem, como atestam, por exe mplo, as inclinações à ordem, limpeza e parcimônia que tendem a surgir como 
substitutos do erotismo anal nas crianças. Na verdade, pode -se afirmar que, na perspectiva freudiana, há uma leitura do desenvolvimento infantil na qual o conflito interno entre diferentes orientações, que se alternam no domínio da personalidade, é parte integrante desse desenvolvimento - visão bastante afinada com o modo de funcionamento da formação reativa. Já na teorização reichiana, como existe a suposição de uma estrutura que atua com alto grau de harmonia interna e flexibilidade (o caráter genital), a formação reativa é associada apenas à estrutura que vive em permanente conflito (o caráter neurótico). Assim, mesmo considerando uma certa mescla entre essas duas formações caracteriológicas, podemos dizer que, diferentemente de Freud, Reich concebe o domínio da saúde como um campo no qual a formação reativa não desempenha um papel que possa ser considerado como relevante.

Um cuidado óbvio, mas necessário, no estudo do pensamento desses autores que, como Freud e Reich, construíram ao longo de várias décadas suas abordagens, é o de, dada a dinâmica envolvida nas obras, sempre situar no tempo qualquer posição teórica citada. Tomando esse cuidado como regra e focalizando o lugar que o conceito de formação reativa ocupa no referencial reichiano, cabe registrar que, em um trabalho de 1926, dedicado à área educacional, denominado "Os Pais como Educadores: A Compulsão a Educar e Suas Causas", pode-se verificar um emprego da formação reativa não associado ao campo da patologia. Nesse artigo com fortes contornos freudianos, numa passagem que indica quais seriam as frustrações necessárias que deveriam ser impingidas às crianças, Reich afirma:

Somente aquelas que têm por objeto controlar e canalizar os instintos da criança que representariam um impedimento para sua adaptação à sociedade. Por exemplo, a crueldade natural da criança terá de converter-se, em parte, em sentimento de compaixão, em parte, em atividade social. (Reich, 1926/1975, p. 61)

Destacando especificamente o extrato que sugere a conversão da crueldade natural da criança em compaixão, pode-se inferir que isso seria realizado por meio da formação reativa; o que, no contexto do artigo, é visto de forma positiva. Assim sendo, cabe indagarmos qual dos dois enfoques permaneceu na abordagem reichiana - o contido no artigo "O Caráter Geni- 


\section{Paulo Albertini}

tal ...", de 1929, ou o expresso no texto "Os Pais como Educadores ...", de 1926? Uma apreciação dos caminhos tomados pela obra desse autor após 1929 indica um fortalecimento da posição presente no trabalho "O Caráter Genital ..."; ou seja, a formação reativa como um mecanismo de defesa associado ao campo da patologia.

Já que falamos em crueldade natural da criança, chegou o momento de abordarmos o que Reich pensou sobre um dos pontos centrais de "O MalEstar na Cultura": a agressividade humana. Faremos isso, inicialmente, expondo duas posições teóricas básicas presentes em escritos reichianos a respeito dos impulsos primários humanos. Na primeira, há uma tentativa de ajustar o modelo pulsional dualístico freudiano dentro da nascente teorização reichiana; na segunda, ocorre um abandono do dualismo freudiano em prol de um monismo energético. Em termos temporais, o período de transição da primeira para a segunda posição ocorreu nos anos finais da década de 20 e início dos anos 30.

Um exemplo da primeira posição - dualismo freudiano dentro do nascente enfoque reichiano - pode ser observado no trecho acima citado, em que o autor trabalha com a idéia de uma crueldade natural da criança. Nessa passagem, Reich parece adotar a tese da pulsão de morte e, ao mesmo te mpo, supõe ser possível direcionar essas pulsões para ações socialmente construtivas, por meio de intervenção educativa e da atuação dos mecanismos de sublimação e formação reativa. Dessa forma, ele consegue operar com o modelo pulsional freudiano e, o que imaginamos ser a sua intenção, praticamente anular os possíveis efeitos destrutivos da pulsão de morte. Em "O Caráter Genital e o Caráter Neurótico" há um outro exemplo desse mesmo posicionamento que, pela sua complexa construção, merece ser citado. Usando o mesmo enfoque já explicado de uma economia energética regula da, presente no seu ideal de saúde, o caráter genital, Reich desloca tota lmente a agressão para o domínio da sublimação. Vejamos a construção do autor:

As descargas orgásticas periódicas da tensão libidinal do id reduzem consideravelmente a pressão das exigências pulsionais do id sobre o ego. Pelo fato do id estar basicamente satisfeito, o superego não tem nenhum motivo para ser sádico e, 
portanto, não exerce qualquer pressão especial sobre o ego. Livre de sentimentos de culpa, este apodera-se da libido genital e de certos empenhos pré-genitais do id, satisfazendo -os, e sublima a agressão natural, bem como partes da libido prégenital, em realizações sociais. (Reich, 1933/1995, pp. 174-175)

E como Reich expõe e fundamenta o seu monismo energético? Vamos, inicialmente, investigar esse posicionamento, utilizando como material de análise as três últimas frases do artigo "Os Pais como Educadores ...", de 1926:

Devemos pensar que aprimitiva força vital que a compulsão a educar pretende dominar foi capaz de criar cultura. É lícito outorgar-lhe uma ampla margem de confiança. Será excessivamente ousado declarar que a vida sabe criar, melhor do que ninguém, as suas necessárias formas de existência? (Reich, 1926/1975, p. 68)

Em um primeiro momento nos parece difícil apreender a forma como Reich concluiu esse artigo. Como tornar compatível a idéia de uma "primit iva força vital...capaz de criar cultura" com o modelo freudiano que supõe a existência de dois grupos de pulsões, eros e thânatos, eternamente em conflito? Segundo nossa interpretação, ao invés de tentar conciliar essas duas perspectivas, o mais indicado é entender esse trecho reichiano como um indício do caminho que, em anos subse qüentes, será trilhado pelo autor. Esse caminho é o de um monismo energético e, ao nosso ver, suas raízes devem ser buscadas, sobretudo, no pensamento do filósofo francês contemporâneo Henri Bergson. Em termos sintéticos, pode-se dizer que Reich materializou a idéia bergsoniana de um princípio vital criador, o élan vital. Em 1942, descrevendo a influência de Bergson em sua obra, Reich afirmou:

A minha atual teoria da identidade e da unidade do funcionamento psicofísico teve a sua origem no pensamento bergsoniano (...) Durante algum tempo, fui encarado como um "bergsoniano maluco" (...) ${ }^{15}$ O princípio de uma força criativa governa ndo a vida não podia ser negado. (Reich, 1942/1978, p. 30)

15 Reich recebeu esse apelido durante o transcorrer de seu curso de medicina em Vi ena, realizado de 1918 a 1922. 


\section{Paulo Albertini}

Segundo nossa interpretação, conceitos centrais do enfoque reichiano ganham maior densidade quando estudados à luz das idéias do filósofo francês. A título de breve registro, note-se que, em "A Evolução Criadora", de 1907, Bergson usa o termo couraça, ou carapaça, com o mesmo sentido básico com que Reich o emprega extensivamente em sua obra, ou seja, como uma defesa que, pelo seu aspecto de cronicidade, ao mesmo tempo, protege e limita. A própria noção de caráter genital adquire maior relevo quando entendida como uma estrutura com alto grau de liberdade; na verdade, um sucesso de élan vital, pois o projeto desse princípio bergsoniano é o de inserir o maior número possível de indeterminação na matéria.

Ainda nos anos finais da década de 20, afinado com esse princípio de uma força criativa primária, vai aparecendo e tomando cada vez mais espaço nos escritos reichianos a noção de auto-regulação ${ }^{16}$, entendida como competência espontânea, primária, visceral da própria vida. Como já afirmamos em outro trabalho (Albertini, 1994, p. 69), esse conceito implica na suposição de uma espécie de racionalidade instintiva; uma confiança na razão da natureza, nos seus mecanismos regulatórios e compensatórios. De acordo com essa orientação teórica, o fundamental é não perder os vínculos com essa capacidade vital e, além disso, propiciar condições ambientais para o seu pleno exercício. Como pode ser notado, Reich se contrapõe ao modelo dualístico freudiano, associando à idéia de conflito, uma perspectiva energética monista ligada à noção de capacidade auto-regulatória. Essa percepção favorável que o autor vai progressivamente construindo em relação ao mundo instintivo, involuntário, biológico, em última instância, em relação à na-

16 Como se sabe, diversos autores, especial mente os ligados à corrente humanista da psicologia, como Kurt Goldstein, Abraham Maslow e Carl Rogers, ou ainda o dissidente da psicanálise Carl G. Jung, além de Jean Piaget, este no campo da epistemologia genética, mesmo que com diferentes denominações, construíram seus enfoques teóricos empregando a idéia de autoregulação. Na esfera dos estudos sobre o pensamento reichiano, na tese de doutorado de Bellini (1993), o leitor pode encontrar um histórico dos primórdios dessa concepção no campo da física e sua larga utilização, no século XIX, na área da biologia. 
tureza $^{17}$, pode ser verificada em um excerto de 1942, quando Reich procura retratar o "extrato humano mais profundo":

Por baixo disso, na profundidade, existem e agem a socialidade e a sexualidade naturais, a alegria espontânea no trabalho e a capacidade para o amor. Esse... mais profundo estrato, que representa o cerne biológico da estrutura humana, é inconsciente e temido. Está em desacordo com todos os aspectos da educação e do controle autoritário. Ao mesmo tempo, é a única esperança real que o homem tem de dominar um dia a miséria social. (Reich, 1942/1978, p.200-201)

Após essa exposição das duas posições teóricas presentes no pensamento reichiano do final da década de 20 e início dos anos 30, a respeito dos impulsos primários humanos, temos condições de, finalmente, sintetizarmos a visão desse autor sobre o tema agressividade. Respeitando a ordem temporal, na primeira concepção há uma tendência em anular os possíveis efeitos destrutivos da pulsão de morte por meio de formações reativas e, principalmente, da sublimação. Dessa forma, mesmo quando Reich parece tentar operar de acordo com o modelo dualístico freudiano, ele organiza o material - sobretudo quando descreve o seu ideal de saúde, o caráter genital - de forma a resultar em algo muito distante da noção de agressividade humana contida em "O MalEstar na Cultura". Já na segunda posição teórica, com o monismo reichiano, a idéia de pulsão de morte é completamente afastada e o autor deixa de conceber a agressividade como algo associado ao domínio primário, instintivo, pulsional, que, supostamente, exigiria satisfação. Nessa última elaboração, a agressividade é vista como um acompanhante necessário de qualquer manifestação afirmativa de vida. Isso não significa que a

17 A nosso ver, a orientação que o enfoque reichiano está assumindo no final dos anos 20, de certa forma o filia ao pensamento do filósofo genebriano que viveu no século XVIII, Jean-Jacques Rousseau. Além do estilo iconoclasta presente nos dois aut ores, Rousseau também tendeu a atribuir os problemas humanos a circunstâncias sociais e, muito antes de Bergson e Reich, ajudou a construir uma visão positiva da natureza. Sobre esse último ponto, no seu tratado sobre a educação, Emílio: $O u$ Da Educação, o genebriano referiu-se à natureza como algo "que tudo faz do melhor modo" (Rousseau, 1762/1999, p. 70). No campo da teoria política, um estudo que explora a aproximação entre Reich e Rousseau é o de Barreto (2000). 
ação destrutiva não exista; porém, ela é entendida como uma formação secundária, produto da não realização da tendência construtiva mais profunda. Vejamos, no próprio texto reichiano, uma boa explicação desse posicionamento:

\begin{abstract}
Agressão, no sentido estrito da palavra, não tem nada a ver com sadismo ou com destruição. A palavra significa "aproximação". Toda manifestação positiva da vida é agressiva: o ato do prazer sexual assim como o ato de ódio destrutivo, o ato sádico assim como o ato de procurar alimento... Agressão é sempre uma tentativa de prover os meios para a satisfação de uma necessidade vital. Assim, a agressão não é um instinto, no sentido estrito da palavra; consiste mais no meio indispensável de satisfação de todo impulso instintivo. Este último é essencialmente agressivo po rque a tensão exige satisfação. (Reich, 1942/1978, p. 139)
\end{abstract}

\title{
Considerações finais
}

A partir da fundamentação desenvolvida neste trabalho, podemos afirmar que, por volta do final dos anos 20, época a que Reich se refere no trecho da entrevista que inspirou este artigo, esse autor discordava frontalmente de teses centrais do pensamento freudiano contidas em "O MalEstar na Cultura". Há divergências profundas quanto à forma de conceber as três noções especialmente focalizadas neste estudo: sexualidade, agressividade e formação reativa. Em linhas gerais, enquanto Freud operava de acordo com um dualismo pulsional e, de forma coerente com as características do modelo adotado, apontava para determinadas dificuldades inevitáveis do sujeito e da relação deste com a cultura; Reich, embasado numa profunda confiança na natureza, representada em seus escritos por princípios como o de autoregulação, tendia a atribuir essas dificuldades a fatores socioculturais passíveis de alteração. Imbuído dessa leitura do makestar humano - e, conseqüentemente, supondo a possibilidade de um bem-estar - Reich volta-se, inteiramente, para o combate das circunstâncias sociais cerceadoras da abgria de viver. Com essa orientação, o caminho a ser seguido era o de Berlim, palco de intensa agitação social, e não o da tradicional Viena, marcada, no núcleo 
psicanalítico, pela tentativa de neutralidade política freudiana. Na Alemanha, no início dos anos 30, filiourse ao Partido Comunista Alemão, e procurou, sem sucesso, levar a perspectiva psicanalítica da subjetividade para o seio desse partido, no período, dominado pela visão estalinista; além disso, envolveurse, teórica e pessoalmente, na luta contra o nazifascismo ascendente e no combate cultural contra a moral sexual repressiva.

Por fim, julgamos necessário registrar uma última ponderação sobre a relação de Reich com o pensamento freudiano. Faremos isso porque, neste estudo, focalizamos um certo estrato dessa relação e não toda a dinâmica envolvida. Objetivamos, com isso, não induzir o leitor a tomar o todo pela parte. Dessa forma, apreciando o conjunto dos escritos reichianos e, ainda que correndo o risco de alguma simplificação, supomos que a relação de Reich com o referencial freudiano comporta três momentos.

Num primeiro, Reich aprende com o mestre, assume determinado conjunto das idéias freudianas e, também, começa a elaborar um desenvolvimento pessoal das mesmas. Em nosso estudo, esse conteúdo foi basicamente exposto no tópico Raízes do pensamento reichiano em Freud. O segundo momento corresponde ao confronto entre os dois autores, fase em que, Reich se coloca especialmente contra os caminhos tomados pela abordagem freudiana e rejeita alguns de seus postulados nodais. Ao centrarmos nosso trabalho na fundamentação das posições reichianas que se opõem ao pensamento freudiano contido em "O MałEstar na Cultura", em geral, investigamos as idéias desse segundo momento. Contudo, é necessário registrar que essa dinâmica relação não se esgota aí. Assim, por exemplo, em um texto de 1951, denominado "Cosmic Superimposition" (Reich, 1951/1973), o autor lança a hipótese de que, na história do desenvolvimento do homem, a couraça teria surgidojuntamente com o aparecimento da consciência e tal fato teria inaugurado um medo primário, da mudança, da perda do controle voluntário e do prazer. O que chama a atenção nesse tipo de reflexão é o fato de Reich não tender a atribuir a origem dos problemas humanos somente a fatores socioculturais passíveis de transformação. Entra em cena, aqui, a complexidade de um sujeito dividido e uma determinada leitura de dificuldades inerentes ao homem. Será possível encontrar, aí, uma certa volta ao 
olhar freudiano exresso em trabalhos como "O MałEstar na Cultura"? Supomos que sim. Porém..., já se faz tarde. Deixemos a investigação dessa hipótese para uma outra oportunidade.

Albertini, P. (2003). Reich and the ossibility of well-being in culture Psicologia USP, 14(2), 61-89.

Abstract: In an interview given in 1952 Reich declared that Freud's Civilization and its discontents had been written as a reply to one of his conferences at Freud's house on the prophylaxis of neurosis. Inspired by Reich's words, this paper aims at investigating which of his thesis could be put against Freud's thought in Civilization and its discontents. Freud and Reich's points of view are differentiated based on the notions of inevitable conflict (Freud) and possibility of harmony (Reich). The paper focuses on the notions of sexuality, aggressiveness and reactive formation.

Index terms: Reich, Wilhelm. Freud, Sigmund. Sexuality. Aggressiveness. Reactive formation.

Albertini, P. (2003). Reich et la possibilite du bien-etre dans la culture. Psicologia USP, 14(2), 61-89.

Résumé: Dans une entrevue donnée en 1952, Reich a affirmé que le texte freudien le malaise dans la culture a été écrit en réponse à une conférence qu'il donna chez Freud sur le thème de la prophylaxie des névroses. Inspiré par ce témoignage, ce travail étudie les thèses reichiennes qui s'opposent à la pensée freudienne de le malaise dans la culture. Les positions des auteurs sont différenciées à partir du conflit inévitable (Freud) et de la possibilité d'harmonie (Reich). Les principales notions mises en valeur sont : la sexualité, l'agressivité et la formation réactive.

Mots clés: Reich, Wilhelm. Freud, Sigmund. Sexualité. Agressivité. Formation réactive. 
Reich e a Possibilidade do Bem-Estar na Cultura

\section{Referências}

Abraham, K. (1970). A formação do caráter no nível genital do desenvolvimento da libido. In K. Abraham, Teoria psicanalítica da libido: Sôbre o caráter e o desenvolvimento da libido (C. M. Oiticica, trad., pp. 195-205). Rio de Janeiro: Imago.

Albertini, P. (1994). Reich: História das idéias e formulações para a educação. São Paulo: Ágora.

Albertini, P. (1997). A sexualidade e o processo educativo: Uma análise inspirada no referencial reichiano. In J. G. Aquino (Org.), Sexualidade na escola: Alternativas teóricas e práticas (pp. 53-70). São Paulo: Summus.

Barreto, A V. de B. (2000). A revolução das paixões: Os fundamentos da psicologia política de Wilhelm Reich. São Paulo: Annablume; FAPESP.

Bellini, L. M. (1993). Afetividade e cognição: O conceito de auto-regulação como mediador da atividade humana em Reich e Piaget. Tese de doutorado, Instituto de Psicologia, Universidade de São Paulo, São Paulo.

Bergson, H. (1964). A evolução criadora (A. C. Monteiro, trad.). Rio de Janeiro: Delta. (Trabalho original publicado em 1907)

Ferraz, F. C. (1997). Das neuroses atuais à psicossomática. In F. C. Ferraz \& R. M. Volich (Orgs.), Psicossoma: Psicossomática psicanalítica (pp. 23-38). São Paulo: Casa do Psicólogo.

Freud, S. (1972). Três ensaios sôbre a teoria da sexualidade. In S. Freud, Edição standard brasileira das obras psicológicas completas de Sigmund Freud (J. Salomão, trad., Vol. 7, pp. 135-250). Rio de Janeiro: Imago. (Trabalho original publicado em 1905)

Freud, S. (1974). O futuro de uma ilusão. In S. Freud, Edição standard brasileira das obras psicológicas completas de Sigmund Freud (J. Salomão, trad., Vol. 21, pp. 1571). Rio de Janeiro: Imago. (Trabalho original publicado em 1927)

Freud, S. (1974). O mal-estar na civilização. In S. Freud, Edição standard brasileira das obras psicológicas completas de Sigmund Freud (J. Salomão, trad., Vol. 21, pp. 81-171). Rio de Janeiro: Imago. (Trabalho original publicado em 1930)

Freud, S. (1976). Além do princípio do prazer. In S. Freud, Edição standard brasileira das obras psicológicas completas de Sigmund Freud (J. Salomão, trad., Vol. 18, pp. 17-85). Rio de Janeiro: Imago. (Trabalho original publicado em 1920)

Freud, S. (1976). Moral sexual "civilizada" e doença nervosa moderna. In S. Freud, Edição standard brasileira das obras psicológicas completas de Sigmund Freud (J. 


\section{Paulo Albertini}

Salomão, trad., Vol. 9, pp. 187-208). Rio de Janeiro: Imago. (Trabalho original publicado em 1908)

Freud, S. (1976). A sexualidade na etiologia das neuroses. In S. Freud, Edição standard brasileira das obras psicológicas completas de Sigmund Freud (J. Salomão, trad., Vol. 3, pp. 289-312). Rio de Janeiro: Imago. (Trabalho original publicado em 1898)

Freud, S. (1976). Sobre os critérios para destacar da neurastenia uma síndrome particular intitulada "neurose de angústia". In S. Freud, Edição standard brasileira das obras psicológicas completas de Sigmund Freud (J. Salomão, trad., Vol. 3, pp. 107-135). Rio de Janeiro: Imago. (Trabalho original publicado em 1895)

Higgins, M., \& Raphael, C. (Orgs.). (1979). Reich fala de Freud (B. S. Nogueira, trad.). Lisboa, Portugal: Moraes. (Trabalho original publicado em 1967)

Jones. E. (1979). Vida e obra de Sigmund Freud (M. A. M. Mattos, trad.). Rio de Janeiro: Zahar. (Trabalho original publicado em 1961)

Laplanche, J., \& Pontalis, J. C. (1983). Vocabulário da psicanálise (P. Tamen, trad.). São Paulo: Martins Fontes. (Trabalho original publicado em 1967)

Mezan, R. (1991). Freud: A trama dos conceitos. São Paulo: Perspectiva.

Reich, W. (1973). Cosmic superimposition. In W. Reich, Ether, God and devil / Cosmic superimposition (pp. 163-301). New York: Farrar, Straus and Giroux. (Trabalho original publicado em 1951)

Reich, W. (1975). Os pais como educadores: A compulsão a educar e suas causas. In W. Reich Conselho Central dos Jardins de Infância Socialistas de Berlim; Schmidt, V. Elemento s para uma pedagogia anti-autoritária (J. C. Dias, A. Sousa, A. Ribeiro, \& M. C. Torres, trads., pp. 53-68). Porto, Portugal: Escorpião. (Trabalho original publicado em 1926)

Reich, W. (1978). A função do orgasmo: Problemas econômico-sexuais da energia biológica (M. G. Novak, trad.). São Paulo: Brasiliense. (Trabalho original publicado em 1942)

Reich, W. (1982). O assassinato de Cristo: Volume um de a peste emocional da humanidade (C. R. L. Viana, trad.). São Paulo: Martins Fontes. (Trabalho original publicado em 1953)

Reich, W. (1995). O caráter genital e o caráter neurótico. In W. Reich, Análise do caráter (M. L. Branco \& M. M. Pecegueiro, trads., pp. 165-185). São Paulo: Martins Fontes. (Trabalho original publicado em 1933)

Rousseau, J. J. (1999). Emílio: Ou da Educação (R. L. Ferreira, trad.). São Paulo: Martins Fontes. (Trabalho original publicado em 1762) 
Reich e a Possibilidade do Bem-Estar na Cultura

Vieira, W. de C. (1994). O branco e o vermelho: Estudo sobre a sexualidade feminina. Tese de doutorado, Instituto de Filosofia e Ciências Humanas, Universidade Estadual de Campinas, Campinas.

Wagner, C. M. (1996). Freud e Reich: Continuidade ou ruptura? São Paulo: Summus.

Wilhelm Reich: Biographical material - history of the discovery of the life energy. (1953). Rangely, Maine: Orgone Institute Press.

Recebido em 04.09.2003

Aceito em 17.09.2003 